\title{
Use of Silica Fume in Stabilizing Cement-Dune Sand for Highway Materials
}

\author{
M. Anisur Rahman, Ali Ahmed* \\ Department of Civil Engineering, Stamford University Bangladesh, Dhaka, Bangladesh \\ Email address: \\ anisur@yahoo.com (M. A. Rahman), aliahmed@stamforduniversity.edu.bd (A. Ahmed) \\ ${ }^{*}$ Corresponding author
}

\section{To cite this article:}

M. Anisur Rahman, Ali Ahmed. Use of Silica Fume in Stabilizing Cement-Dune Sand for Highway Materials. American Journal of Civil Engineering. Vol. 5, No. 1, 2017, pp. 41-49. doi: 10.11648/j.ajce.20170501.16

Received: November 26, 2016; Accepted: December 8, 2016; Published: January 18, 2017

\begin{abstract}
This study presents the potential of silica fume (SF) in the stabilization of cement and dune sand for road bases and sub-bases. Ordinary Portland Cement (OPC) was used as a stabilizer and SF as an additive. Employed percentages of cement were $0,6,9$ and 12 , and silica fume/cement $(\mathrm{SF} / \mathrm{C})$ ratios were $0,0.2,0.4$ and 0.6 . Various geotechnical properties such as grain size distribution, maximum dry density (MDD), optimum moisture content (OMC), unconfined compressive strength (UCS), California bearing ratio (CBR), swell and wet-dry durability were studied. Test results showed that all these geotechnical properties were improved with the addition of both cement and SF. From the point of view of efficiency and economy, SF/C ratio of 0.20 would be called as "optimum ratio". On the basis of UCS, CBR value, swell, soil-cement loss and mix proportion, this investigation recommends mix proportions $(\% \mathrm{SF}+\%$ cement $+\%$ sand $)$ of $1.8+9.0+100$ and $0+12+$ 100 for base materials and $1.2+6+100$ for sub-base materials.
\end{abstract}

Keywords: Silica Fume, Dune Sand, Stabilizer, Strength Criteria, Durability, Base and Sub-Base Materials

\section{Introduction}

\subsection{General}

Most of the developing countries of the world have been suffering from acute shortage of conventional construction materials due to the ever increased constructions of roads, highways, bridges, buildings etc. for the continual increase of the growth of population. With this fastest growth of suburban areas, it has been incrementally necessitated searching for new construction materials, which can be used as an alternative or partial replacement of conventional materials such as cement, well graded aggregates etc. If the industrial waste and/or locally available abundant materials could be utilized in construction work, the construction industry would be benefited and the environment could be protected from pollution. In this research work, two of such materials SF and dune sand have been chosen to serve the purposes.

The improvement of the geotechnical properties of a soil by the addition of admixtures is generally called as soil stabilization, particularly in base and sub-bases of highway construction. This process of improving properties of soils has been practicing for centuries. In many parts of the world, pozzolanic materials such as lime, fly ash, ground bottom ash, volcanic ash, rice husk ash, scoria etc. are being used in soils in order to improve the properties of the less stable soils. In recent decades, there has been considerable interest in improving the properties of cement products by incorporating SF as a potentially beneficial material. Since the early part of 1980s, investigation about and use of SFadditives in concrete and cementitious materials had begun in many parts of the world, including North and South America, Europe, South Africa, East Asia like Japan and the Middle East.

\subsection{Background of the Study}

The high surface area of SF could accelerate hydration reaction in concrete [1]. The effect of SF on the strength development in concrete was carried out by replacing cement up to $20 \%$ [2]. SF is a reactive pozzolan and very effective filler. Because of these qualities, it has prominent effects on the properties of cement-based products [3-6]. The UCS of concrete mixes containing SF (by replacing 0 to $20 \%$ cement) are almost the same up to 7 days, but after 7 days of curing, the pozzolanic effect of the SF dominates the strength 
development [7]. SF has a distinct property to bind the alkali $\left(\mathrm{K}_{2} \mathrm{O}\right.$ and $\left.\mathrm{Na}_{2} \mathrm{O}\right)$ present in OPC and it also reduces the detrimental alkali-aggregate reaction [8].

In the coastal area of the Arabian Peninsula, concrete structures are being deteriorated rapidly due to high concentrations of chlorides and sulphates combined with high temperatures. Chloride from sea water can contaminate structures, roads and highways constructed along the sea coast even several hundred meters away from the sea. Many researchers $[9,10]$ utilized the SF in concrete and found the dramatic reduction in rate of chloride diffusion in their investigations. OPC with SF additive protects better than sulphate resistance cements against chloride initiated corrosion and it also provides protection against sulphates like sulphate resistant cement does [11]. Most forms of chemical attack on concrete are typified either by leaching of calcium hydroxide or ingress of harmful and disruptive substances such as sulphates or nitrates. SF reduces the amount of soluble calcium hydroxide and thus reduces the risk of leaching. SF also reduces the permeability of concrete [12] and it retards penetrating deleterious substances into the concrete. Consequently, concrete with SF poses superior resistance to chemical attack.

Although dune sand is abundantly available in Saudi Arabia as well as in other Middle East countries, a few efforts have been made on the stabilization of dune sand for construction work. Dune sand has been stabilized with asphalt-cement kiln dust (CKD) mixes and promising results have been reported by few researchers [13]. It has been found that CKD-stabilized dune sand can be utilized for base materials in highway construction work [14].

The effect of SF as partial replacement of cement on the strength characteristics of concrete was studied [15] and the optimum percentage of SF was determined as $10 \%$. The addition of SF had greatly improved the water impermeability, the carbonation resistance and the freeze-thaw resistance of concrete composites [16]. Combined use of lime-water and SF enhances the pozzolanic reaction and it was identified by the strength development at both early and later ages [17]. SF inclusion increased the workability and strength of concrete considerably and the optimum dose of SF was found as 5\% (by weight) replacement of OPC [18]. It was reported that silica fume is very effective in the design and development of high strength performance concrete [19]. Shanmugapriya and others reported that the replacement of cement by SF up to $7.5 \%$ showed gradual increase in the strength of concrete [20]. The incorporation of dune sand powder form substitution to Portland cement yields a new variety of cement compound with physicalmechanical properties superior to those of Portland cement [21]. Guettala and Mezghiche have studied on cement paste containing dune sand powder and identified the occurrence of pozzolanic reaction [22]. Alhozaimy and others found that autoclaved curing can promote the pozzolanic reactivity of dune sand and therefore, greatly increases the concrete strength [23]. It was showed that the fine particles improved the workability and strength of concrete made with dune sand [24]. Guettala and Mezghiche observed the development of compressive strength and hydration of cement pastes due to addition of dune sand powder [25]. It was found that lime-silica fume caused an increase in the angle of internal friction of dune sand [26]. The replacement of cement by $10 \%$ of SF improved both mechanical and durability performances of recycled aggregate concrete [27]. The strength of mortar cube lost its strength due to the addition of cenosphere, but the strength loss could be compensated by adding SF [28]. Unsoaked CBR on compacted dune sands treated with lime-silica fume exhibited higher CBR values than compacted untreated dune sands [29]. When the dune sand underneath and around a footing is injected by slurry of limesilica fume, there will be an increase in the ultimate bearing capacity of footing by nineteen times [30].

\subsection{Objective of the Study}

Statistical study shows that hundreds of thousands of tonnes of SF produces every year during the production of silicon and ferro-silicon alloys. As SF has pertinent qualities of replacing cement, enhancing material property and durability, it can be utilized in other civil engineering work such as in soil stabilization besides application in concrete. The construction industry would be significantly benefited if SF could be used as partial replacement of cement and dune sand as an alternative to depleting well graded materials. The main objective of this study is to examine the potential of SF on UCS, CBR and durability characteristics of cement-stabilized dune sand and thus, to find the optimum mix proportions which can produce suitable base and sub-base materials for highway construction.

\section{Materials}

\subsection{Dune Sand}

The soil used in this investigation was collected from Makkah Road (thirteen kilometres from) Jeddah in Saudi Arabia. These are wind or aeolin deposits called dune sands as these are deposited like a dune or mound [31]. Winds often demolish the dune and redeposit it at a new location. Dune sands are problematic soils having poor grading, but abundantly available in Saudi Arabia.

\subsection{Silica Fume}

The SF used in this work was supplied by Elkem materials Co., Kristians and S., Norway. Elkem SF is called as micro silica. It was densified (920-D) and beneficiated condensed silica fume (CSF). CSF is a byproduct of the smelting production of silicon metal and ferrosilicon alloys. CSF is called microsilica when it is beneficiated. Beneficiation includes quality control involving classification and other required action in order to maintain the contents of possible deleterious materials below acceptable levels. Chemical compositions and physical properties of Elkem SF are given in Table 1. Its main constituent is silica and it contains minor oxides of other elements such as potassium, magnesium, iron, aluminium, calcium, sodium etc. It has a very high specific surface area of $18-28 \mathrm{~m}^{2} / \mathrm{g}$, a sign of highly active material. It can be noted that the range of specific surface area of cement and fly ash are $0.2-0.5 \mathrm{~m}^{2} / \mathrm{g}$ and $0.2-0.6 \mathrm{~m}^{2} / \mathrm{g}$, respectively. 


\subsection{Cement}

Cement was supplied by Arabian Cement Co., Jeddah, Saudi Arabia. It was OPC, ASTM Type I C-150.

\section{Experimental Procedure}

A number of laboratory tests were performed on original and stabilized dune sands. These tests were grain size analysis, standard Proctor compaction, unconfined compression, CBR and cyclic wetting and drying durability tests. These tests were carried out in accordance with American Society for Testing and Materials (ASTM) specifications for soils. Some additional cares have been taken in mixing and preparation of specimens.

\subsection{Grain Size Analysis}

The particle size distribution of dune sand was determined by dry sieving method as wet sieving and hydrometer methods were not needed for this type of granular soils.

\subsection{Standard Proctor Compaction Test}

Five series of standard Proctor compaction tests (ASTM D558 - 82) were performed to determine the MDD and OMC for different mix proportions of cement and sand. The percentages of cement (by weight of sand) were $0,3,6,9$ and 12. The standard Proctor compactive energy was followed, because this can easily be achieved in the field.

\subsection{Unconfined Compression Test}

Several series of unconfined compression tests were performed for different mix proportions of SF, OPC and dune sand. Mix proportions $(\% \mathrm{SF}+\%$ cement $+\%$ sand $)$ were $0+6$ $+100,1.2+6+100,2.4+6+100,3.6+6+100,0+9+100$, $1.8+9+100,3.6+9+100,5.4+9+100,0+12+100,2.4+$ $12+100,4.8+12+100$ and $7.2+12+100$ in percentages by weight of dry sand These are shown in Table 3. Cylindrical specimens of $50 \mathrm{~mm}$ diameter and $100 \mathrm{~mm}$ height were prepared at the same MDD and OMC obtained in standard Procter compaction test. A length/diameter ratio of 2.0 was maintained for all test specimens. The procedures followed in the preparation of cylindrical specimens are given below:

a) Cement was spread on a non-absorbent tray. Required amount of SF was added on the top of the cement. SF and cement were dry-mixed by hand with the help of a trowel. Mixing was continued until uniform color was achieved. Then, required amount of sand was spread on another non-absorbent tray and premixed SF-cement was added on the top of the sand. Again, dry-mixing was continued until SF, cement and sand were uniformly mixed. Premeasured water was added and mixed with SF-cement-sand mixture. Care was taken to ensure that the whole mixture was uniform and thorough.

b) The mixture was poured inside a cylindrical mould by three layers. Each layer was compacted by tamping rod and scratched properly to avoid joint between layers. Mould was filled up with the premeasured amount of mixture in order to obtain required dry density. Then, sample was finally compacted inside the mould with the help of a Versa tester. Care was taken to ensure uniform compaction throughout the length of the specimen.

c) Specimen was extruded from the mould with the help of a universal extruder. Then, it was wrapped by wax paper and sealed adequately by means of molten wax so that no moisture could be lost during the period of curing.

d) Specimens were placed in a chamber where the temperature and the relative humidity were maintained at about $20^{\circ} \mathrm{C}$ and $95 \%$, respectively to cure for 7,28 and 56 days.

e) Nine specimens were prepared for each mix proportion and average UCS of three specimens was considered, i.e., a total number of 108 cylindrical specimens were prepared, cured and sheared for unconfined compression test. All these specimens were sheared under strain-controlled test at a rate of $1.25 \mathrm{~mm} \mathrm{~min}^{-1}$.

\subsection{California Bearing Ratio Test}

Several soaked CBR tests were carried out on stabilized soil in accordance with British Standard 1377 [32]. Samples containing OMC were compacted in CBR mould with the same compactive energy per volume as in the standard Proctor compaction test. Specimens were water cured for 96 hours after 7 days moist cured and percentages of swelling were recorded at the end of water curing. Penetration testing was carried out with the help of a 30 tonne Versa tester machine and a plunger of cross-sectional area of $19.35 \mathrm{~cm}^{2}$. The rate of penetration was $1.27 \mathrm{~mm} \mathrm{~min}^{-1}$ and CBR value was calculated corresponding to $2.54 \mathrm{~mm}$ penetration.

Table 1. Chemical composition of silica fume.

\begin{tabular}{|c|c|c|c|}
\hline Chemical composition & Results [\%] & Physical properties & Results \\
\hline Silicon dioxide $\left(\mathrm{SiO}_{2}\right)$ & $86-96$ & Particle density & $2.2 \mathrm{Mg} / \mathrm{m}^{3}$ \\
\hline Aluminium oxide $\left(\mathrm{Al}_{2} \mathrm{O}_{3}\right)$ & $0.4-1.0$ & Bulk density & $0.5-0.7 \mathrm{Mg} / \mathrm{m}^{3}$ \\
\hline Ferric oxide $\left(\mathrm{Fe}_{2} \mathrm{O}_{3}\right)$ & $0.1-1.5$ & Specif. surf. area & $18-28 \mathrm{~m}^{2} / \mathrm{g}$ \\
\hline Calcium oxide $(\mathrm{CaO})$ & $0.1-0.5$ & ${ }^{*} \mathrm{CP}>44 \mu \mathrm{m}$ & $<1.0 \%$ \\
\hline Sodium oxide $\left(\mathrm{Na}_{2} \mathrm{O}\right)$ & $0.4-0.5$ & - & - \\
\hline Potassium oxide $\left(\mathrm{K}_{2} \mathrm{O}\right)$ & $0.3-3.0$ & - & - \\
\hline Magnesium oxide (MgO) & $0.3-2.0$ & - & - \\
\hline Carbon (C) & $0.5-2.5$ & - & - \\
\hline
\end{tabular}

${ }^{*} \mathrm{CP}$ - Coarse particles 


\subsection{Wetting and Drying Durability Test}

Cyclic wetting and drying tests (ASTM D559-82) were carried out to determine the durability of the stabilized soils instead of freezing and thawing test as the earlier one is more justified in arid and semi-arid regions. Samples were compacted in standard Proctor mould at the same MDD and $\mathrm{OMC}$ as found in the standard Proctor compaction test. Soilcement loss was recorded at the end of 12 cycles.

\subsection{Mechanism of Silica Fume Reaction}

In order to understand the results of the testing program, it is necessary to refer a brief background on the mechanism of $\mathrm{SF}$ reaction with OPC. In the hydration process of OPC, both tricalcium and dicalcium silicates $\left(\mathrm{C}_{3} \mathrm{~S}\right.$ and $\left.\mathrm{C}_{2} \mathrm{~S}\right)$ liberate calcium hydroxide, i.e.,

$$
\begin{aligned}
& 2\left(3 \mathrm{CaO}, \mathrm{SiO}_{2}\right)+6 \mathrm{H}_{2} \mathrm{O} \rightarrow 3 \mathrm{CaO}, 2 \mathrm{SiO}_{2}, 3 \mathrm{H}_{2} \mathrm{O}+3 \mathrm{Ca}(\mathrm{OH})_{2} \\
& 2\left(2 \mathrm{CaO}, \mathrm{SiO}_{2}\right)+4 \mathrm{H}_{2} \mathrm{O} \rightarrow 3 \mathrm{CaO}, 2 \mathrm{SiO}_{2}, 3 \mathrm{H}_{2} \mathrm{O}+\mathrm{Ca}(\mathrm{OH})_{2}
\end{aligned}
$$

In concrete or any cement-based products, the weak and easily soluble calcium hydroxide can be as much as $20 \%$ to $25 \%$ by weight of cement paste, while the rest of the paste mainly consists of calcium silicate hydrate i.e., C-S-H [C = $\mathrm{CaO}, \mathrm{S}=\mathrm{SiO}_{2}$ and $\mathrm{H}=\mathrm{H}_{2} \mathrm{O}$ ], which forms the binding agent. When pozzolanic materials are added, the weak and easily soluble $\mathrm{Ca}(\mathrm{OH})_{2}$ is transformed to $\mathrm{C}-\mathrm{S}-\mathrm{H}$, i.e.,

$$
3 \mathrm{Ca}(\mathrm{OH})_{2}+2 \mathrm{SiO}_{2} \rightarrow 3 \mathrm{CaO}, 2 \mathrm{SiO}_{2}, 3 \mathrm{H}_{2} \mathrm{O}
$$

This forms a basis for further improvement of both strength and durability of any cement-based products due to the addition of pozzolanic materials.
SF has excellent pozzolanic properties due to its high amorphous silica contents and high specific surface area. During the course of hydration of OPC, the high degree of pozzolanic reactivity of SF converts some of the less useful calcium hydroxide crystals into beneficial C-S-H gel binder. The main contribution of the pozzolanic reaction of SF to strength development takes place in the time from 3 to 28 days at $20^{\circ} \mathrm{C}[33]$.

SF also acts as effective filler. This filler is responsible for the distribution of hydration products in a more homogenous fashion in the space available. In other words, SF, a filler, acts as a nucleating agent and accelerates hydration of OPC. The combined pozzolanic and filler effects manifest themselves in a refined porosity and thus, turn the cement based mix in a much more dense microstructure [6]. The refinement of pore structure directly enhances the mechanical properties of cement based products.

\section{Evaluation Criteria for Road Bases and Sub-bases}

Soil-cement materials are usually accepted on the basis of satisfying strength and durability requirements. Strength is generally assessed from UCS or CBR test results. Some Standards also use the triaxial compression test results. The durability of soil-cement in terms of percentage of soil-cement loss is assessed from cyclic wetting and drying tests and/or freezing and thawing tests, and the percent of swell from CBR test. Usual and conventional standard specifications for road

\begin{tabular}{|c|c|c|c|c|c|}
\hline \multirow{2}{*}{ Purpose } & \multicolumn{4}{|c|}{ After Ingles and Metcalf, 1972} & \multirow{2}{*}{$\begin{array}{l}{ }^{*} \mathrm{UCSC} \\
\mathrm{UCS}[\mathrm{MPa}]\end{array}$} \\
\hline & UCS [MPa] & CBR $[\%]$ & Swell [\%] & Soil-cement loss [\%] & \\
\hline Road base & $1.37-5.49$ & $200-600$ & 2 & 14 & 1.73 \\
\hline
\end{tabular}
bases and sub-bases are shown in Table 2 .

Table 2. Soil-cement evaluation criteria for base and sub-base materials.

*UCSC - Usual and conventional strength criteria

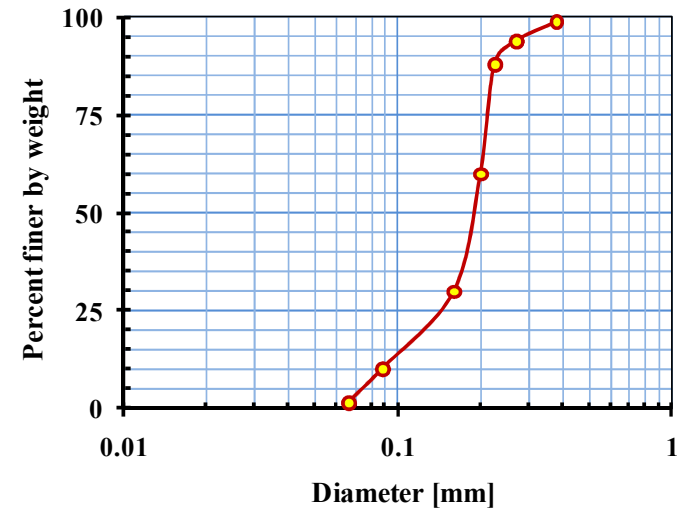

Figure 1. Grain size distribution curve of the investigated dune sand.

\section{Test Results and Discussion}

\subsection{Grain Size Analysis of Dune Sand}

The particle size distribution curve of dune sand is presented in Figure 1. The values of co-efficient of uniformity $\left(C_{u}\right)$ and co-efficient of curvature $\left(C_{c}\right)$ are found 2.33 and 1.53 , respectively. The dune sand is classified into A-3 group soil in accordance with American Association of State Highway and Transportation Officials (AASHTO) method of classification. This sand is poorly graded and not standard mortar sand (ASTM C144). 


\subsection{Compaction Characteristics of Cement-Dune Sand Mixes}

The results of the standard Proctor compaction tests on different cement-sand mixes are presented in Table 3, while the addition of cement contents. This figure clearly shows that the MDD increases almost linearly with increase in cement contents. At $12 \%$ of cement, the MDD has increased by about $7 \%$. On the other hand, the OMC of sand decreases with increase in cement contents. The rate of decrease is not linear. At $12 \%$ of cement, the OMC has decreased by about $15 \%$.

The above mentioned compaction characteristics are attained due to the facts that the voids of the poorly graded sands are being filled up by the fine-grained cement and it co-operates to increase the MDD. In addition, the watercement paste acts as a lubricating agent to ease the compaction process. Consequently, it reduces the $\mathrm{OMC}$ and increases the MDD.

\subsection{UCS of Stabilized Dune Sand}

\subsubsection{Effect of SF/C Ratio on UCS}

UCS of different mix proportions of SF, cement and dune sand at different ages are presented in Table 4 . Figure 3 shows the trends of changes of UCS with SF/C ratio for different cement contents and ages. The UCS increases with increase in SF/C ratio. The rate of increase in UCS is linear and steeper up to SF/C ratio of 0.4 for 6 and $9 \%$ cement. In the case of $12 \%$ cement, it is steeper only up to $\mathrm{SF} / \mathrm{C}$ ratio of 0.2 . Then, the rate of increase in UCS decreases. The amount of SF up to $\mathrm{SF} / \mathrm{C}$ ratio of 0.2 is more efficient and prominent considering for all cement contents $(6,9$, and $12 \%)$. From the points of view of both efficiency and economy, a $\mathrm{SF} / \mathrm{C}$ ratio of 0.2 could be called as "optimum ratio". Figure 2 shows the nature of changes of MDD and OMC with

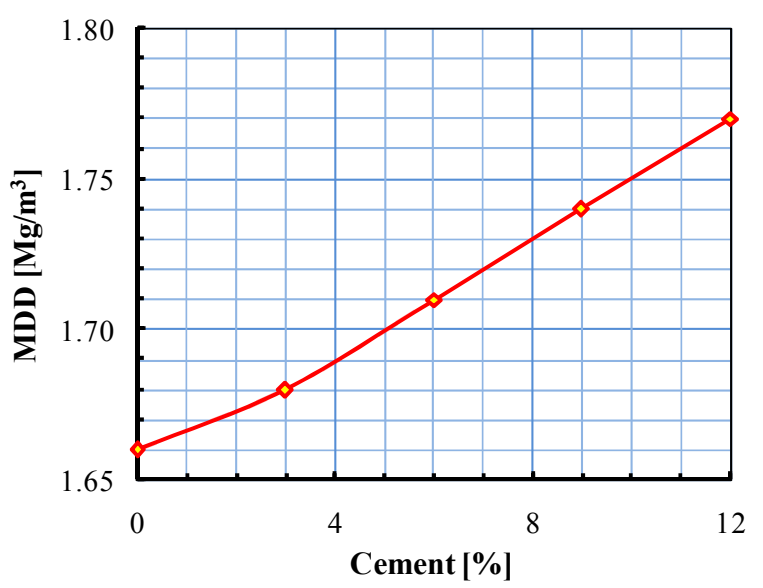

(a) Maximum dry density (MDD)

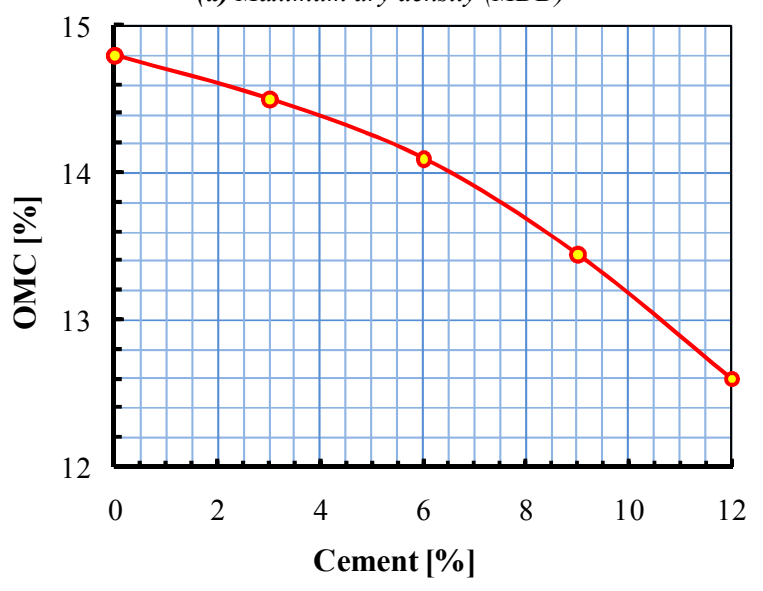

(b) Optimum moisture content (OMC)

Figure 2. Effect of stabilizer (cement) on MDD and OMC of dune sand.

\subsubsection{UCS Development with Age}

Figure 4 shows the changes of UCS with respect to ages for different cement contents and SF/C ratios. There exists strength development in the stabilized soil for all cement contents and SF/C ratios. These developments in UCS are non-linear. The nature of the shape of the curves is almost the same for all cement contents.

Table 3. Mix Proportions and compaction characteristics of dune sand-cement-silica fume.

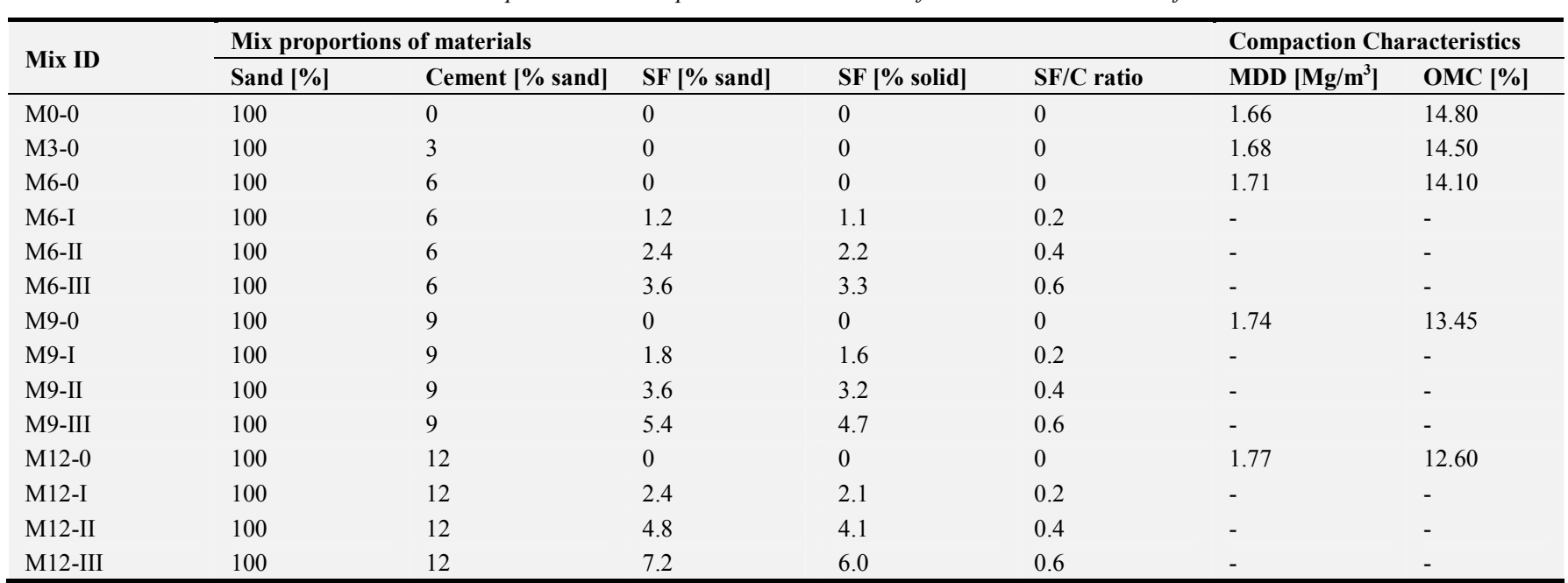


Table 4. Unconfined compressive strength and strength ratio of stabilized dune sand at different ages.

\begin{tabular}{lllllll}
\hline \multirow{2}{*}{ Mix ID } & \multicolumn{2}{l}{ Unconfined compressive strength [MPa] } & & Strength ratio & & \\
\cline { 2 - 7 } & 7-day & 28-day & $\mathbf{5 6 - d a y}$ & $\mathbf{S}_{\mathbf{2 8}} / \mathbf{S}_{\mathbf{7}}$ & $\mathbf{S}_{\mathbf{5 6}} / \mathbf{S}_{\mathbf{7}}$ & $\mathbf{S}_{\mathbf{5 6}} / \mathbf{S}_{\mathbf{2 8}}$ \\
\hline M6-0 & 0.63 & 0.89 & 0.99 & 1.41 & 1.57 & 1.11 \\
M6-I & 0.68 & 1.37 & 1.84 & 2.01 & 2.71 & 1.34 \\
M6-II & 0.69 & 1.96 & 2.72 & 2.84 & 3.94 & 1.39 \\
M6-III & 0.74 & 2.15 & 2.92 & 2.91 & 3.95 & 1.36 \\
M9-0 & 1.45 & 2.05 & 2.27 & 1.41 & 1.57 & 1.11 \\
M9-I & 1.67 & 2.79 & 3.30 & 1.67 & 2.46 & 1.18 \\
M9-II & 1.76 & 3.58 & 4.33 & 2.03 & 1.21 \\
M9-III & 1.87 & 3.83 & 4.67 & 2.05 & 1.50 & 1.22 \\
M12-0 & 2.20 & 3.07 & 3.70 & 1.40 & 2.11 & 1.21 \\
M12-I & 2.56 & 4.48 & 6.40 & 1.75 & 2.00 & 1.21 \\
M12-II & 3.07 & 5.13 & 6.53 & 1.67 & 2.04 & 1.20 \\
M12-III & 3.20 & 5.39 & & 1.68 & 1.21 \\
\hline
\end{tabular}

Note: $\mathrm{S}_{7}=7$-day strength, $\mathrm{S}_{28}=28$-day strength, $\mathrm{S}_{56}=56$-day strength

The 7, 28 and 56 days compressive strengths of 6,9 and $12 \%$ of cement mixtures for $\mathrm{SF} / \mathrm{C}$ ratio of 0.2 are $7.9,53.9$ and $85.9 \%, 15.2,36.1$ and $45.4 \%$, and $16.4,45.9$ and $45.9 \%$, respectively higher than those of cement without SF $(6,9$ and $12 \%$ of cement alone). It indicates that strength development at higher ages (28 days or more) is much more significant than that at early ages ( 7 days or less).

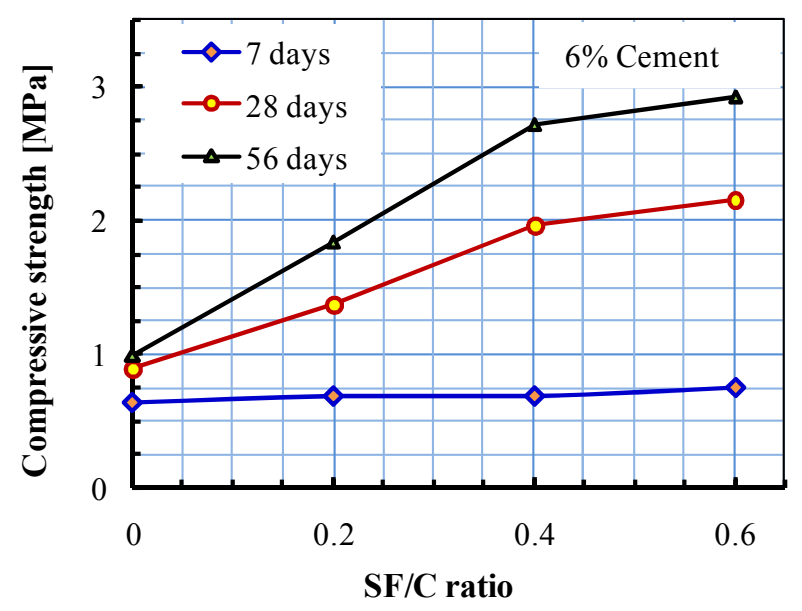

(a) $6 \%$ cement

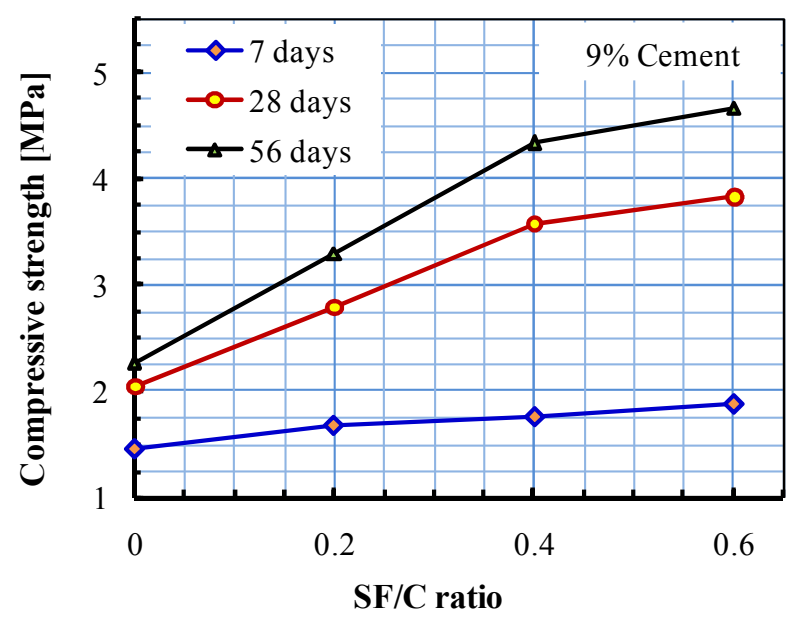

(b) $9 \%$ cement

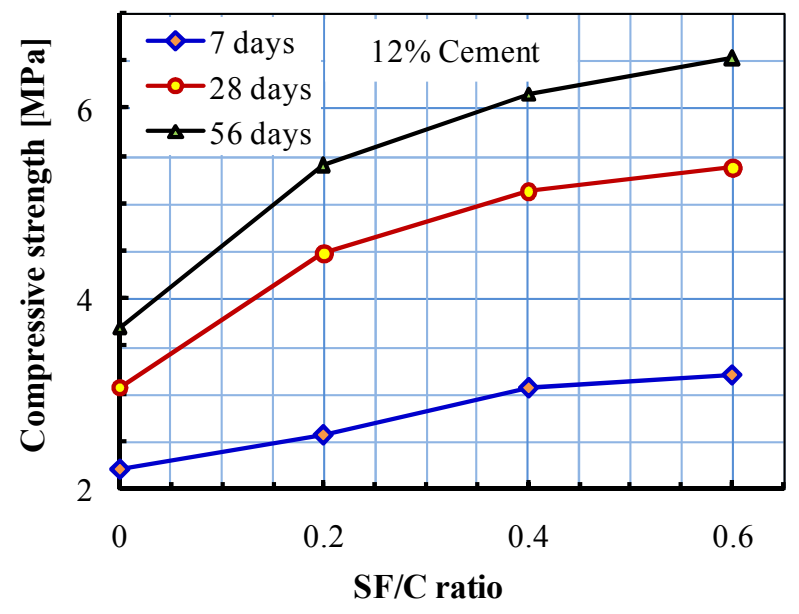

(c) $12 \%$ cement

Figure 3. Effect of $S F / C$ ratio on UCS of stabilized dune sand.

Figure 4 also shows that the rate of strength development of specimens containing SF is higher (steeper) from 7 to 28 days compared to specimens without SF. After 28 days, the rate of strength development of all specimens with or without $\mathrm{SF}$ is almost the same. These observations indicate that SF is highly pozzolanic and it reacts much more rapidly than other pozzolans. In the case of other pozzolans, long-term strength effects are more significant than the short-term effects. The major contribution of pozzolanic reaction of SF to strength development takes place in the period from 3 to 28 days at about $20^{\circ} \mathrm{C}$ [33]

\subsubsection{Effect of SF on Strength Ratios}

Strength ratios of $\mathrm{S}_{28} / \mathrm{S}_{7}, \mathrm{~S}_{56} / \mathrm{S}_{7}$ and $\mathrm{S}_{56} / \mathrm{S}_{28}$ for various mix proportions of SF, cement and sand are shown in Table 4. The nature of changes of strength ratios with $\mathrm{SF} / \mathrm{C}$ ratios are also presented in Figure 5. It could be seen from the Table 4 that strength ratios of $\mathrm{S}_{56} / \mathrm{S}_{7}$ and $\mathrm{S}_{28} / \mathrm{S}_{7}$ for specimens containing SF are higher than those of specimens containing cement alone, i.e., the strength ratios of $\mathrm{S}_{56} / \mathrm{S}_{7}$ and $\mathrm{S}_{28} / \mathrm{S}_{7}$ increase with increase in $\mathrm{SF} / \mathrm{C}$ ratio. This is due to the pozzolanic effects of SF which becomes more prominent after 7 days. The strength ratios of $\mathrm{S}_{56} / \mathrm{S}_{28}$ for all specimens with or without SF are nearly same, unlike the strength ratios of 
$\mathrm{S}_{56} / \mathrm{S}_{7}$ and $\mathrm{S}_{28} / \mathrm{S}_{7}$. The reason behind this is that the major contribution of the pozzolanic reaction of SF to strength development already took place earlier than 56 days.

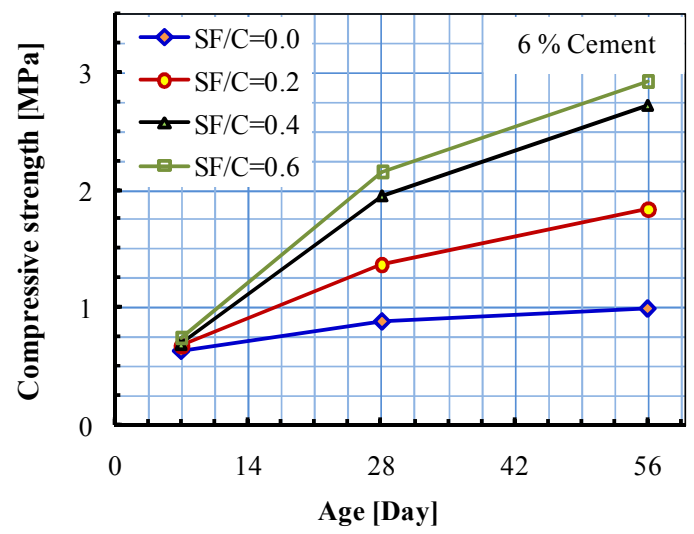

(a) $6 \%$ cement

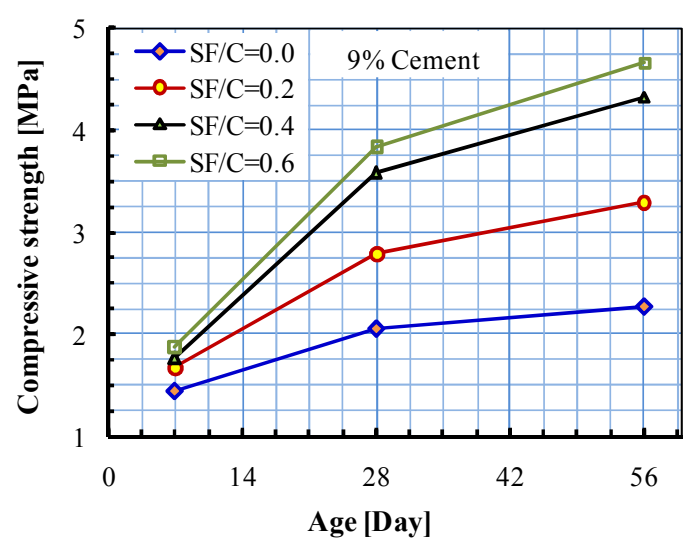

(b) $9 \%$ cement

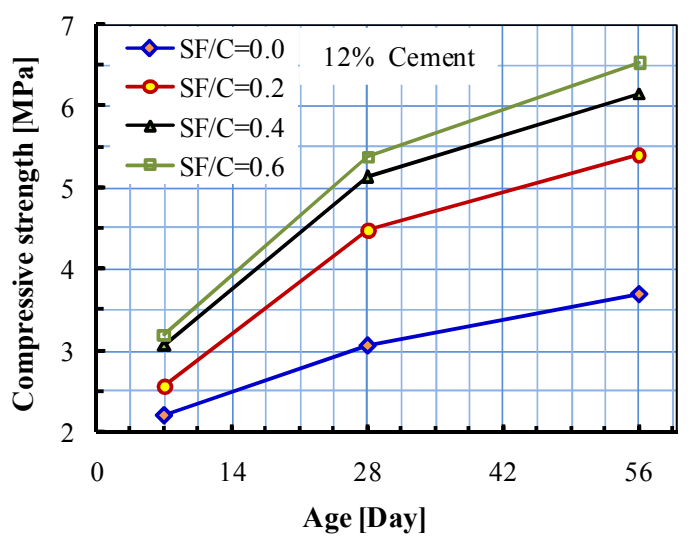

(c) $12 \%$ cement

Figure 4. Strength development of stabilized dune sand with different ages for different $S F / C$ ratios.

Table 4 shows that the strength ratios of $\mathrm{S}_{56} / \mathrm{S}_{7}$ and $\mathrm{S}_{28} / \mathrm{S}_{7}$ are higher at lower percentages of cement contents for the same $\mathrm{SF} / \mathrm{C}$ ratio. Because the particles of SF, cement and sand would be relatively less closely contacted at lower percentages of cement and SF. So, the pozzolanic reaction would be less rapid, i.e., the rate of strength development would be lower and prolonger. Consequently, the strength ratios of $\mathrm{S}_{56} / \mathrm{S}_{7}$ and $\mathrm{S}_{28} / \mathrm{S}_{7}$ would be higher at lower percentages of cement contents. On the other hand, the particles of cement, SF and sand would be more closely contacted in the case of higher percentages of cement contents and SF. So, the pozzolanic reaction would take place faster and the rate of strength development would be higher. Thus, the strength ratios of $\mathrm{S}_{56} / \mathrm{S}_{7}$ and $\mathrm{S}_{28} / \mathrm{S}_{7}$ would be lower in the case of higher percentages of cement contents.

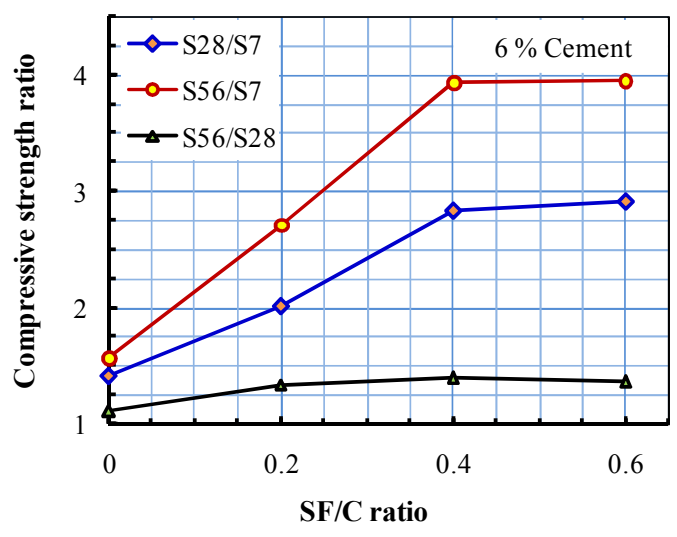

(a) $6 \%$ cement

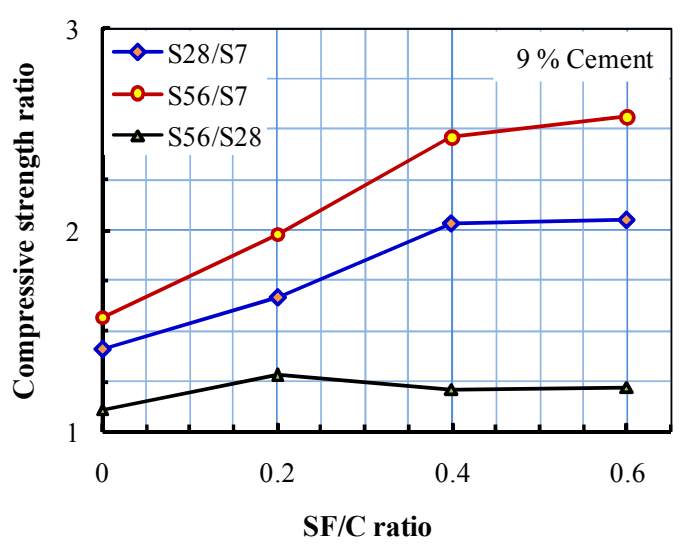

(b) $9 \%$ cement

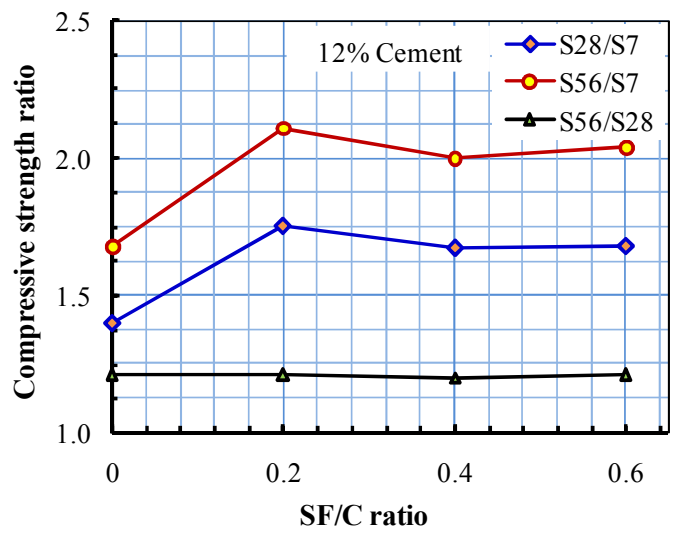

(c) $12 \%$ cement

Figure 5. Effect of $S F / C$ ratio on the strength ratio (at different ages) of stabilized dune sand. 


\subsection{CBR of Stabilized Dune Sand}

\subsubsection{CBR Value and Swell of SF-Cement-Sand Mixes}

Results of soaked CBR tests on various mix proportions of $\mathrm{SF}$, cement and sand are presented in Table 5. The soaked CBR value and swell of pure dune sand were found $24.8 \%$ and $0 \%$, respectively. The CBR value increased prominently with increase in both SF and cement contents. No swelling was observed for all mix proportions. There was a substantial increment in CBR value at the addition of $20 \%$ SF, i.e., at $\mathrm{SF} / \mathrm{C}$ ratio of 0.2 . It is also justified and expected because of the combined pozzolanic and filler effects of SF.

Table 5. California bearing ratioand soil-cement lossofSF-cement-dune sand mixes.

\begin{tabular}{llll}
\hline \multirow{2}{*}{ Mix ID } & \multicolumn{2}{l}{ Soaked CBR value } & Wet-dry durability \\
\cline { 2 - 4 } & CBR [\%] & Swell [\%] & Soil-cement loss [\%] \\
\hline M0-0 & 24.8 & 0 & - \\
M6-0 & 143.0 & 0 & 6.80 \\
M6-I & 193.0 & 0 & 6.20 \\
M6-II & 240.0 & 0 & 5.95 \\
M6-III & 286.0 & 0 & 5.90 \\
M9-0 & 316.0 & 0 & 4.70 \\
M9-I & 418.0 & 0 & 3.80 \\
M9-II & 513.0 & 0 & 3.41 \\
M9-III & 591.0 & 0 & 3.35 \\
M12-0 & 511.0 & 0 & 3.70 \\
M12-I & - & - & 3.30 \\
M12-II & - & - & 3.15 \\
M12-III & - & - & 3.11 \\
\hline
\end{tabular}

\subsubsection{Soil-Cement Loss of SF-Cement-Dune Sand Mixes}

Results of cyclic wet-dry durability tests on SF-cementdune sand mixes are presented in Table 5. Soil-cement losses of all mix proportions were less than $7 \%$. Soil-cement loss decreased with the addition of both SF and cement. It is rightly expected because the presence of SF refines and makes denser the pore structure of cement-products, and thus, the permeability of cement-products decreases. Consequently, the soil-cement loss decreases with the presence of SF.

\subsection{Evaluation of Stabilized Dune Sand for Base and Sub-base Materials}

In the evaluation, specimens containing SF more than $20 \%$ $(\mathrm{SF} / \mathrm{C}=0.2)$ are not considered because mixes containing SF more than $20 \%$ are less efficient and not economical as stated earlier. It could be noticed from the Tables 2, 4 and 5 that the stabilized sand of mix proportion of $1.2+6+100(\% \mathrm{SF}+\%$ cement $+\%$ sand) satisfies all the requirements of UCS, CBR value, swell and soil-cement loss for road sub-base materials. A mix proportion of $0+9+100$ satisfies the requirements (Table 2) of UCS, CBR, swell and soil-cement loss [34] for road base materials. But, it does not satisfy usual and conventional UCS requirement of $1.73 \mathrm{MPa}$. It is observed that the mix proportions of $1.8+9+100$ and $0+12+100$ satisfy all requirements (Table 2) for base materials. Hence, this study recommends a mix proportion of $1.2+6+100$ for sub-base, and mix proportions of $1.8+9+100$ and $0+12+$ 100 for base materials.

In practice, SF-cement-sand mixes could not be sealed by wax and cured in a humid room as in the laboratory. It is suggested that SF-cement-sand mixes need to be cured by the help of wet gunny bags or jute bags in the field to avoid moisture loss. Alternatively, water sprinkling method can also be used for curing. It was found that the sprinkling water curing produced almost the same strength of blocks at 56 days as the humid curing [35].

\section{Conclusions}

On the basis of the test results of the investigated dune sand, this study found that geotechnical properties of dune sand are improved with the addition of cement and SF; with the increase in cement content, MDD of sand increases, but OMC decreases. Moreover, the investigation about the use of cement and silica fume on stabilization of base and subbase materials showed that UCS increases with the addition of both cement and SF; the rate of increment in strength is higher and steeper up to the addition of $20 \%$ SF. As SF was more efficient at $\mathrm{SF} / \mathrm{C}$ ratio of 0.2 , this ratio could be called as "optimum ratio"; with the addition of cement and SF, CBR value is substantially increased and soil cement loss is also improved; the strength ratios of $\mathrm{S}_{56} / \mathrm{S}_{7}$ and $\mathrm{S}_{28} / \mathrm{S}_{7}$ are higher for higher $\mathrm{SF} / \mathrm{C}$ ratios. But the strength ratio of $\mathrm{S}_{56} / \mathrm{S}_{28}$ is almost the same for all specimens irrespective of $\mathrm{SF} / \mathrm{C}$ ratio. At the same $\mathrm{SF} / \mathrm{C}$ ratio, the strength ratios of $\mathrm{S}_{56} / \mathrm{S}_{7}$ and $\mathrm{S}_{28} / \mathrm{S}_{7}$ are higher at the lower percentages of cement and SF. $6 \%$ cement and $1.2 \%$ SF combination (i.e., $\mathrm{SF} / \mathrm{C}$ ratio of 0.2 ) satisfies all requirements for road subbase materials. The combinations of $9 \%$ cement and $1.8 \%$ $\mathrm{SF}$, and $12 \%$ cement without SF satisfy all requirements for base materials.

\section{References}

[1] O. E. Gjorv and K. E. Loland, "Condensed silica fume in concrete", Proc. of Nordic Research Seminar, Report BML 82.610, Division of Building materials, The Norwegian Institute of technology, NTH, Trondheim, 1982, pp. 293.

[2] M. Sandvik, "Mathematical models of the strength development of concrete and application on concrete with and without the addition of condensed silica fume", Dr.ing Thesis, Report BML 84.101, Division of Building Materials, The Norwegian Institute of Technology, NTH, Trondheim, 317, 1984.

[3] S. Diamond, "Very high strength cement-based materials - a prospective", MRS Symposia Proc., J. F. Young (Ed.), Pittsburgh, vol. 42, 1985, pp. 233.

[4] L. Hjorth, "Microsilica in concrete", Publication No.1, Nordic Concrete Research, 1982.

[5] M. Regourd, "Condensed silica fume", Aitcin, P. C. (Ed.), University de Sherbrooke, Quebec, Canada, 1983.

[6] E. J. Sellevold, D. H. Bager and J. K. Klitgoard, "Silica fumecement pastes, hydration and pore structure", Report No. 82.610, Division of Building materials, Norwegian Institute of Technology, NTH, Trondheim, 1982, pp. 19-50. 
[7] M. Sandvik and O. E. Gjorv, "Effect of condensed silica fume on the strength development of concrete", $2^{\text {nd }}$ International Conference on the Use of Fly Ash, Silica Fume, Slag and Natural Pozzolans in Concrete, Madrid, Spain, vol. 2, 1986, pp. 893-901.

[8] A. D. Buck, and J. P. Burkes, "Characterization and reactivity of silica fume", 3rd International Conference on Cement Microscopy, Houston, Texas, 1981, pp. 279-289.

[9] S. Marusin, "Chloride ion penetration in conventional concrete and concrete containing microsilica fume", $2^{\text {nd }}$ International Conference on the Use of Fly Ash, Microsilica Fume, Slag and Natural Pozzolans in Concrete, Madrid, Spain, vol. 2, 1986, pp. 1119-1133.

[10] O. Gautefall, "Effect of condensed silica fume on the diffusion of chlorides through hardened cement paste", $2^{\text {nd }}$ International Conference on the Use of Fly Ash, Microsilica Fume, Slag and Natural Pozzolans in Concrete, Madrid, Spain, vol. 2, 1986, pp. 991-997.

[11] O. E. Gjorv, "Durability of concrete containing condensed silica fume", $1^{\text {st }}$ International Conference on the Use of Fly Ash, Silica Fume, Slag and Other Mineral by-Products in Concrete, Montebello, Canada, II, 1983, pp. 695-708.

[12] N. Banthia, M. Pigeon, J. Marchand and J. Boisvert, "Permeability of roller compacted concrete", J. of Material in Civil Engg., ASCE, vol. 4(1), 1992, pp. 27-40.

[13] M. N. Fatani, and A. M. Khan, "Improvement of dune sand asphalt mixes for pavement bases", J. of King Abdulaziz University of Engineering Sciences, Jeddah, K. S. A., vol. 2, 1990, pp. 35-47.

[14] Z. A. Baghdadi and M. A. Rahman, "The potential of cement kiln dust for the stabilization of dune sand in highway construction", Building and Environment, U. K., vol. 25(4), 1990, pp. 285-289.

[15] L. Singh, A. Kumar and A. Singh, "Study and partial replacement of cement by silica fume", International Journal of Advanced Research, vol. 4, Issue 7, 2016, pp. 104-120.

[16] P. Zhang and Q. F. Li, "Durability of high performance concrete composites containing silica fume", Journal of Materials: Design and Applications, vol. 227(4), 2012, pp. 343-349.

[17] A. A. A. E. Metwally and M. F. Ghazy, "Performance of Portland cement mixes containing silica fume and mixed with lime-water", HBRC Journal, vol. 10, 2014, pp. 247-257.

[18] V. Srivastava, R. Kumar, V. C. Agarwal and P. K. Mehta, "Effect of silica fume on workability and compressive strength of OPC concrete", Journal of Environment and Nanotechnology, vol. 3, No. 3, 2014, pp. 32-35.

[19] S. Refat, "Utilization of silica fume in concrete: Review of hardened properties", Resources Conservation and Recycling, vol. 55(11), September, 2011, pp. 923-932.

[20] T. Shanmugapriya, R. N. Uma, R. K. Satish and S. Kaveen, "A characteristics study of high performance concrete with silica fume and M-sand", International Journal of Applied Engineering Research, vol. 10, No. 2, 2015, pp. 4929-4938.

[21] S. Guettala, B. Mezghiche and M. Mellas, "Influence of addition dune sand powder to cement, on the properties physical-mechanical and deformability of concrete", Asian
Journal of Civil Engineering, Building and Housing, vol. 13, no. 6,2012 , pp. $765-781$.

[22] S. Guettala and B. Mezghiche, "Compressive strength and hydration with age of cement pastes containing dune sand powder", Construction and Building Materials, vol. 25, no. 3, 2011, pp. 1263-1269.

[23] A. Alhozaimy, M. S. Jaafar, A. I. Al-Negheimish, A. H. Abdullah,Y. H. Taufiq-Yap, J. Noorzaei and O. A. Alawad, "Properties of high strength concrete using white and dune sands under normal and autoclaved curing", Construction and Building Materials, vol. 27, no. 1, 2012, pp. 218-222.

[24] J. F. Luo, H. Li, P. Zhu, W. H. Duan, X. L. Zhao and F. Collins, "Effect of very fine particles on workability and strength of concrete made with dune sand", Construction and Building Materials, vol. 47, 2013, pp. 31-37.

[25] S. Guettala and B. Mezghiche, "Effect of addition dune sand powder on development of compressive strength and hydration of cement pastes", World Academy of Science, Engineering and Technology, vol. 70, 2012, pp. 198-204.

[26] Y. F. Mohammed, H. J. Hasan and S. A. D. Ahmed, "Strength characteristics of dune sand stabilized with lime-silica fume mix", International Journal of Pavement Engineering, 2016, pp. 1-9. doi:10.1080/10298436.2016.1215687.

[27] M. Saini and S. Goel, "Strength and permeability of recycled aggregate concrete containing silica fumes", International Journal of Innovative Research in Science, Engineering and Technology, vol. 5, Issue 10, 2016, pp. 17675-17682.

[28] K. S. Kannan, L. Andal and M. Shanmugasundaram, “An investigation on strength development of cement with cenosphare and silica fume as pozzolanic replacement", Advances in Materials Science and Engineering, vol. 2016, Article ID 9367619, 5 pages, 2016.

[29] Y. F. Mohammed, H. J. Hasan and S. A. D. Ahmed, "Compaction and collapsecharacteristics of dune sand stabilize with lime-silica fume mix", Earth Sciences Research Journal, vol. 20, no. 2, 2016, pp. 11-18.

[30] Y. F. Mohammed, H. J. Hasan and S. A. D. Ahmed, "Bearing capacity of strip footing resting on dune sands stabilize by grouting with lime-silica fume mix", International Journal of Civil Engineering and Technology, vol. 7, Issue 2, 2016, pp. 01-21.

[31] J. E. Bowles, "Physical and geotechnical properties of soils", International student edition, McGraw Hill Book Co., Singapore, 1985, pp. 107.

[32] Methods of testing soils for civil engineering purposes, B. S. 1377, 1975, British Standard Institution, London, U. K.

[33] E. J. Sellevold and F. F. Radjy, "Condensed silica fume (microsilica) in concrete: Water demand and strength development", $1^{\text {st }}$ International Conference on the Use of Fly Ash, Silica Fume, Slag and Other Mineral by-Products in Concrete, Montebello, Canada, II, 1983, pp. 677-694.

[34] O. G. Ingles and J. B. Metcalf, "Soil stabilization - Principles and Practice", Butterworths, Sydney, N.S.W., 1972, pp. 122.

[35] M. A. Rahman, "Curing of rice husk ash mix sandcrete blocks", International Journal of Structures, Roorkee, India, vol. 8(1), 1988, pp. 57-66. 